\title{
A Product Inhibition Study on Adenosine Deaminase by Spectroscopy and Calorimetry
}

\author{
Ali Akbar Saboury*, Adeleh Divsalar, Ghasem Ataie Jafari ${ }^{\dagger}$ Ali Akbar Moosavi-Movahedi, \\ Mohammad Reza Housaindokht ${ }^{*}$ and Gholam Hosain Hakimelahi ${ }^{\S}$ \\ Institute of Biochemistry and Biophysics, University of Tehran, Tehran, Iran \\ ${ }^{\dagger}$ Faculty of Paramedical Science, Shahid-Beheshti University of Medical Science, Tehran, Iran \\ Department of Chemistry, University of Ferdowsi, Mashhad, Iran \\ ${ }^{\S}$ Institute of Chemistry, Academia Sinica Taipei, Taipei, Taiwan, ROC
}

Received 28 December 2001, Accepted 18 February 2002

\begin{abstract}
Kinetic and thermodynamic studies have been made on the effect of the inosine product on the activity of adenosine deaminase in a $50 \mathrm{mM}$ sodium phosphate buffer, $\mathrm{pH} 7.5$, at $27^{\circ} \mathrm{C}$ using UV spectrophotometry and isothermal titration calorimetry (ITC). A competitive inhibition was observed for inosine as a product of the enzymatic reaction. A graphical-fitting method was used for determination of the binding constant and enthalpy of inhibitor binding by using isothermal titration microcalorimetry data. The dissociation-binding constant is equal to $140 \mu \mathrm{M}$ by the microcalorimetry method, which agrees well with the value of $143 \mu \mathrm{M}$ for the inhibition constant that was obtained from the spectroscopy method.
\end{abstract}

Keywords: Adenosine deaminase, Inosine, Product inhibition, Inhibition constant, Isothermal titration calorimetry

\section{Introduction}

Adenosine deaminase (ADA, EC 3.5.4.4), a key enzyme in purine metabolism, catalyzes the irreversible hydrolytic deamination of active adenosine (or 2'-deoxy-adenosine), which yields the inactive metabolite inosine (or 2'deoxyinosine) and ammonia. It is present in virtually all mammalian cells, and is known to occur in several isoenzymatic and molecular forms (Hirchhorn and Ratech, 1980). A deficiency of ADA activity is associated with a form of severe combined immunodeficiency disease (SCID) (Giblet et al., 1972; Valentine et al., 1977). Also, a 40- to 70-fold increase of its activity is associated with a form of chronic nonspherocytic hemolytic disease (Daddona et al., 1978).

*To whom correspondence should be addressed.

Tel: 0098-21-6498819; Fax: 0098-21-6404680

E-mail: saboury@chamran.ut.ac.ir
Enzyme abnormalities have also been reported in some leukemia diseases (Murray et al., 1985) and in acquired immunodeficiency syndrome (AIDS) (Murray et al., 1985; Wilson et al., 1991). It has been suggested that modulating ADA activity may be a target for chemotherapy. Therefore, ADA inhibitors may be used both as drugs and co-drugs in combination with certain anticancer or antiviral agents which are adenosine analogues (Glazer, 1980a, b; Lee et al., 1984).

ADA is a glycoprotein that consists of a single polypeptide chain of 311 amino acids. It was sequenced in 1984 (Doddona et al., 1984). The primary amino acids sequence of ADA is highly conserved across species (Chang et al., 1991). Studies on the crystal structure of mouse ADA show that the protein is composed of an eight-stranded $\alpha / \beta$ motif with five additional $\alpha$-helices, and the active site is located in the $\beta$-barrel $-\mathrm{COOH}$ terminal end (Wilson et al., 1991). The crystal structure also revealed that $\mathrm{ADA}$ is a metalloenzyme that complexes one mole of $\mathrm{Zn}^{2+}$ per mole of protein. The zinc ion is located deep within the substrate-binding cleft, and coordinated in a tetrahedral geometry to three $\mathrm{N \varepsilon} 2$ atoms of His-15, His-17, and His-214, as well as the O $\delta 2$ of Asp-295. A water molecule, which shares the ligand coordination site with Asp295 , is polarized by the metal that gives rise to a hydroxylate ion that replaces the ammonia at the $\mathrm{C}-6$ position of adenosine through a stereospecific addition-elimination mechanism. Experiments confirm that in the active enzyme, zinc plays a critical role in catalysis (Bhaumik et al., 1993). It was reported that a secondary metal binding site(s) is available that would allow some metal ions to inhibit the holoenzyme (Cooper et al., 1997).

The function of ADA is critical in controlling the effect of adenosine in other systems. Adenosine is an endogenous antihypoxic and anticonvulsant, as well as a modulate of platelet aggregation, lipolysis, glycogenolysis, blood flow, and neurotransmission (McIlwain, 1983; Stone, 1989). Therefore, 
the modulation of ADA with the use of highly specific inhibitors might modify the action of endogenous adenosine under various physiological and pathological conditions (Agarwal, 1982; Phillis et al., 1985; Centelles et al., 1988). In this study, we investigated the inhibitory effect of the inosine product on the enzymatic reaction of ADA by spectroscopy and calorimetric methods.

\section{Material and Methods}

Materials Adenosine deaminase (type IV) from calf intestinal mucosa, adenosine, and inosine were obtained from Sigma. All of the other chemicals were of highest grade available from chemical sources. The solutions were prepared in doubly distilled water.

Enzyme assay The enzyme activity was assayed by uv-vis spectrophotometry using a Shimadzu-3100 instrument. This was followed by a decrease in the absorbance at $265 \mathrm{~nm}$ that is due to the conversion of adenosine to inosine, based on the Kaplan method (Kaplan, 1955), that used the change extinction coefficient of -8400 $\mathrm{M}^{-1} \mathrm{~cm}^{-1}$ for adenosine. The standard assay mixture contained a final volume of $1 \mathrm{ml}$. The concentration of enzyme in the assay mixture was $0.94 \mathrm{nM}$. Assays were carried out in a $50 \mathrm{mM}$ sodium phosphate buffer, $\mathrm{pH}=7.5$. The activities were measured over at least seven different concentrations of adenosine. The assays were repeated at least three times. The adenosine concentration range is between 0.25 to $2.5 K_{m}$. Care was taken to use adequate experimental conditions in order to keep the enzyme reaction linearity during the first minute of the reaction.

Calorimetric measurement The isothermal titration microcalorimetric experiments were performed with the 4-channel commercial microcalorimetric system, Thermal Activity Monitor 2277, Thermometric, Sweden. Each channel is a twin heatconduction calorimeter where the heat-flow sensor is a semiconducting thermopile (multi-junction thermocouple plates) that is positioned between the vessel holders and surrounding heat sink. The insertion vessel was made from stainless steel. The inosine solution $(2 \mathrm{mM})$ was injected by a Hamilton syringe into the calorimetric stirred titration vessel, which contained $1.8 \mathrm{ml}$ enzyme, $0.75 \mathrm{mg} / \mathrm{ml}$, including a phosphate buffer $(50 \mathrm{mM})$, $\mathrm{pH}=7.5$. Thin $(0.15 \mathrm{~mm}$ inner diameter $)$ stainless steel hypodermic needles (permanently fixed to the syringe) reached directly into the calorimetric vessel. The injection of the inosine solution into the perfusion vessel was repeated 20 times. Each injection included $15 \mu \mathrm{l}$ reagent. The calorimetric signal was measured by a digital voltmeter that was part of a computerized recording system. The heat of each injection was calculated by the "Thermometric Digitam 3" software program. The heat of the dilution of the inosine solution was measured as described previously, except the enzyme was excluded. The enthalpy of the dilution was subtracted from the enthalpy of the enzyme-inosine interaction. The enthalpy of the dilution of the enzyme was negligible. The microcalorimeter was frequently calibrated electrically during the course of the study.

In all of the calculations, the molecular weight of ADA was taken to be 34500 (Brady and OSullivan, 1967).

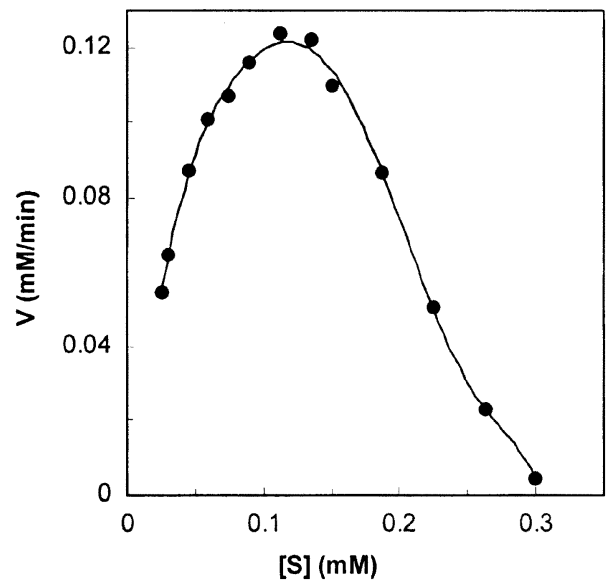

Fig. 1. Activity of $\mathrm{ADA}$ at $\mathrm{pH}=7.5$ and $\mathrm{T}=300 \mathrm{~K}$ in different concentrations of adenosine substrate.

\section{Results and Discussion}

Figure 1 shows the activity of ADA against the adenosine substrate concentration. The decreased activity of ADA above the $0.11 \mathrm{mM}$ concentration of substrate is related to the inhibition of the enzyme by the substrate (Blum and Schwedt, 1998) and product inosine. The double reciprocal LineweaverBurk plots for ADA in different fixed concentrations of inosine $(\mathrm{pH}=7.5$ and $\mathrm{T}=300 \mathrm{~K})$ are shown in Fig. $2 \mathrm{a}$. The value of $V_{\max }$ is unchanged by the inosine, but the apparent Michaelis constant $\left(K_{m}{ }^{\prime}\right)$ value is increased. This confirms the competitive inhibition of inosine on ADA. The values of $K_{m}{ }^{\prime}$ at any fixed concentration of inosine were obtained from Fig. $2 \mathrm{a}$ and plotted versus concentrations of inosine in Fig. $2 b$ (named a secondary plot) in order to obtain the inhibition constant $\left(K_{I}\right)$. The results are as follows:

$$
K_{m}=38 \mu \mathrm{M} K_{I}=143 \mu \mathrm{M}
$$

The Michaelis-Menten constant $\left(K_{m}\right)$ that was obtained from these experiments is identical to that of a previous report (Moosavi-Movahedi et. al, 1993).

By titration of a solution that contained an enzyme (E) with a solution of inhibitor (I), the equilibrium reaction moves toward increasing the concentration of the EI complex. The heat value of the reaction depends on the concentration of the EI complex. Therefore, the reaction under consideration can be written as follows:

$$
\mathrm{EI} \Leftrightarrow \mathrm{E}+\mathrm{I} \quad \mathrm{K}=[\mathrm{E}][\mathrm{I}] /[\mathrm{EI}]
$$

and also

$$
\begin{aligned}
& {[\mathrm{I}]_{\text {total }}=[\mathrm{I}]+[\mathrm{EI}]} \\
& {[\mathrm{E}]_{\mathrm{total}}=[\mathrm{E}]+[\mathrm{EI}]=(\mathrm{K}[\mathrm{EI}] /[\mathrm{I}])+[\mathrm{EI}]}
\end{aligned}
$$

Equation (2) can be solved for [I] and this then substituted into the equation (3), which can then be rearranged to give the quadratic equation its only real root as: 

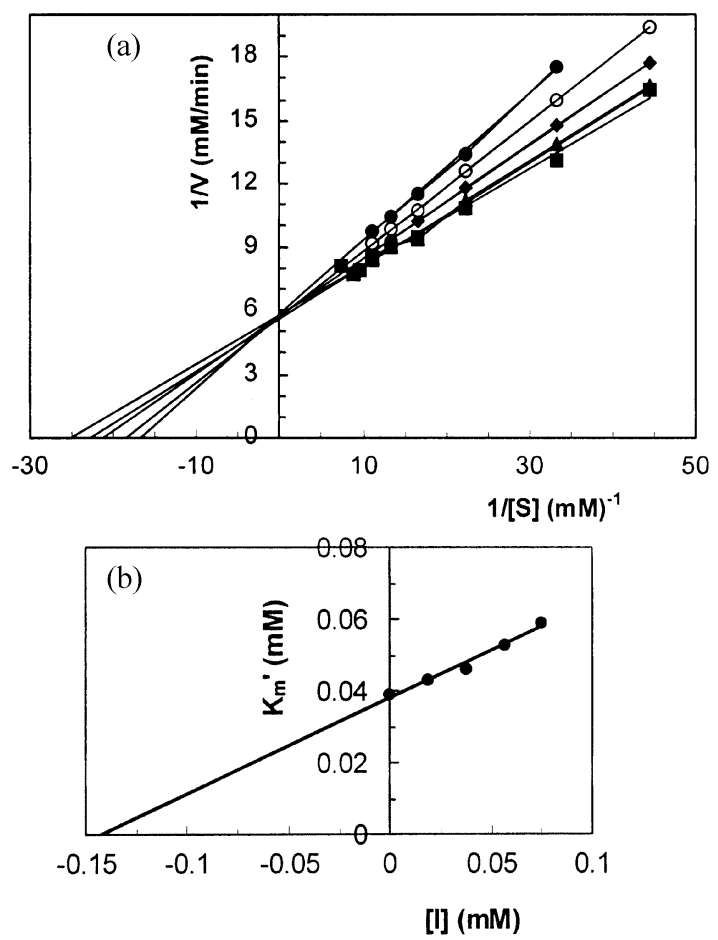

Fig. 2. (a) Double reciprocal Lineweaver-Burk plots for the kinetic of $\mathrm{ADA}$ at $\mathrm{pH}=7.5$ and $\mathrm{T}=300 \mathrm{~K}$ in the presence of different fixed concentrations of inosine: $0 \mu \mathrm{M}(\boldsymbol{\square}), 18.75 \mu \mathrm{M}(\boldsymbol{\Delta}), 37.50 \mu \mathrm{M}$ $(\diamond), 56.25 \mu \mathrm{M}(\bigcirc$ ), and $75.00 \mathrm{mM}(\bigcirc$ ). (b) Secondary plot, $1 /$ [S]-axis intercepts versus [I]; S and I are substrate and inhibitor, respectively.

$$
[\mathrm{EI}]=\left\{(\mathrm{B}+\mathrm{K})-\left[(\mathrm{B}+\mathrm{K})^{2}-\mathrm{C}\right]^{1 / 2}\right\} / 2
$$

where

$$
\mathrm{B}=[\mathrm{E}]_{\text {total }}+[\mathrm{I}]_{\text {total }} \mathrm{C}=4[\mathrm{E}]_{\text {total }}[\mathrm{I}]_{\text {total }}
$$

The sum of the heat evolutions that follows the i:th titration step, $\mathrm{q}_{\mathrm{i}}$, can be expressed as

$$
\mathrm{Q}_{\mathrm{i}}=\Delta \mathrm{H} \mathrm{V}_{\mathrm{i}}[\mathrm{EI}]_{\mathrm{i}}
$$

Where $V_{i}$ is the volume of the reaction solution and $\mathrm{DH}$ is the enthalpy of binding. The combination of equations (4) and (6) will lead to

$$
\Delta \mathrm{H}=1 / \mathrm{A}_{\mathrm{i}}\left\{\left(\mathrm{B}_{\mathrm{i}}+\mathrm{K}\right)-\left[\left(\mathrm{B}_{\mathrm{i}}+\mathrm{K}\right)^{2}-\mathrm{C}_{\mathrm{i}}\right]^{1 / 2}\right\}
$$

where

$$
\mathrm{A}_{\mathrm{i}}=\mathrm{V}_{\mathrm{i}} / 2 \mathrm{Q}_{\mathrm{i}}
$$

$\mathrm{A}_{\mathrm{i}}, \mathrm{B}_{\mathrm{i}}$, and $\mathrm{C}_{\mathrm{i}}$ can be calculated in each injection, so equation (7) contains two unknowns, $\mathrm{K}$ and $\Delta \mathrm{H}$. A series of reasonable value for $\mathrm{K}$ is inserted into equation (7), and corresponding values for $\Delta \mathrm{H}$ are calculated and the graph $\Delta \mathrm{H}$ versus $\mathrm{K}$ is constructed. Curves of all of the titration steps will intersect in one point, which represents the true value for $\Delta \mathrm{H}$ and $\mathrm{K}$.

The data that was obtained from the isothermal titration
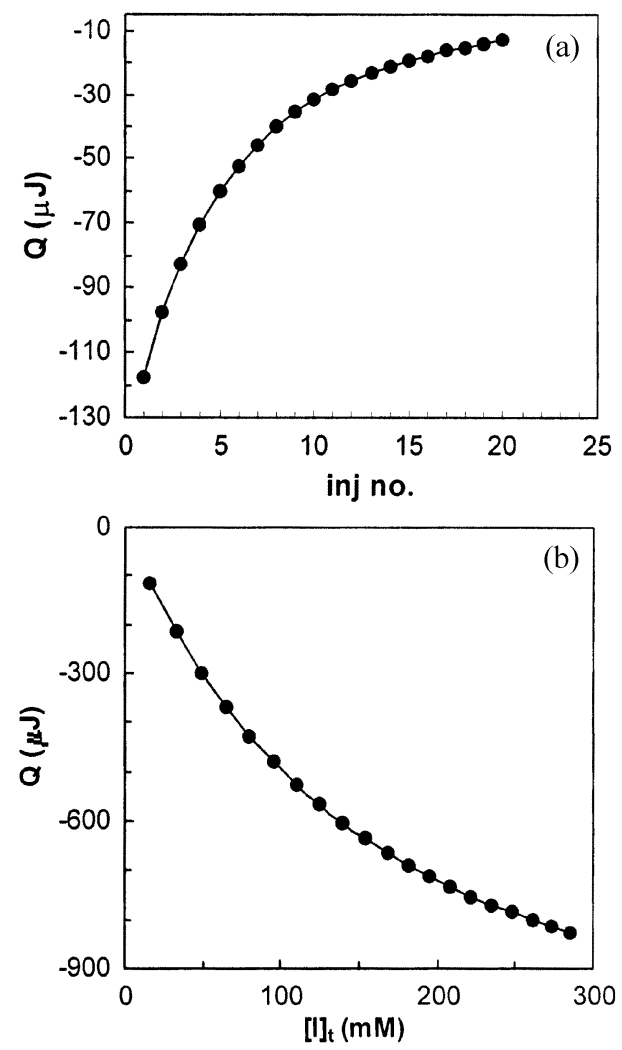

Fig. 3. (a) The heat of the inosine binding on ADA for 20 automatic cumulative injections, each $15 \mu \mathrm{l}$ of the inosine solution, $2 \mathrm{mM}$, into the sample cell that contained $1.8 \mathrm{ml}$ ADA solution at a concentration of $0.75 \mathrm{mg} / \mathrm{ml}(21.7 \mu \mathrm{M})$. (b) The heat of the binding versus the total concentration of inosine (calculated from Fig. 2a).

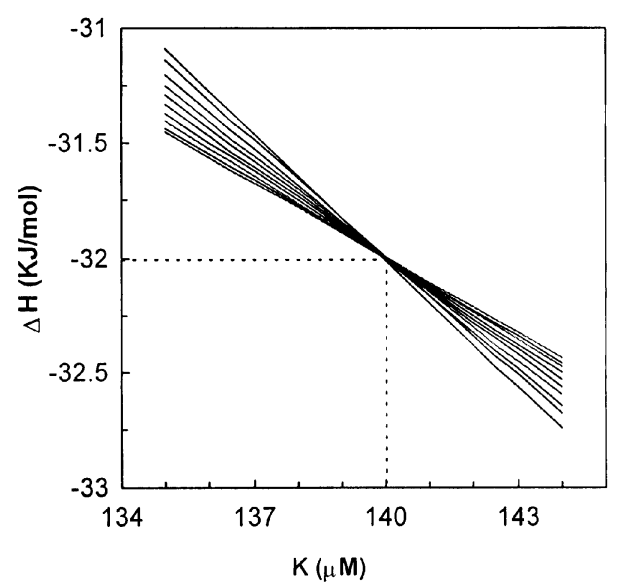

Fig. 4. $\Delta H$ versus $\mathrm{K}$ for the first 10 injections in the reasonable values of $\mathrm{K}$, according to the equation (7). The coordinates of the intersection point of the curves give the true value for $\Delta \mathrm{H}$ and $\mathrm{K}$.

microcalorimetry of the ADA interaction with inosine is shown in Fig. 3. Fig. 3a shows the heat of each injection and Fig. $3 b$ shows the heat that is related to each of the total 
concentrations of inosine. The plots of $\Delta \mathrm{H}$ versus $\mathrm{K}$, according to equation (7), for the first 10 injections are shown in Fig. 4. The intersection of curves gives:

$$
\mathrm{K}=140 \mu \mathrm{M} \quad \Delta \mathrm{H}=-32 \mathrm{~kJ} / \mathrm{mol}
$$

The conformity of the dissociation binding constants $(\mathrm{K})$ obtained from thermodynamic and kinetic studies is observed.

It is concluded that adenosine deaminase is inhibited by the inosine product as a competitive inhibition. Kinetic studies of ADA should be performed below the $2.5 K_{m}$ concentration of the substrate. Moreover, the proposed graphical fitting method for determination of the binding constant and enthalpy of binding in the base of isothermal titration microcalorimetry data is very simple with good accuracy. It can be used in other systems.

Acknowledgments The financial support by the University of Tehran is gratefully acknowledged.

\section{References}

Agarwal, R. P. (1982) Inhibitors of adenosine deaminase. Pharmacol. Ther. 17, 399-429.

Phillis, J. W., De Long, E. R. and Towner, K. J. (1985) Adenosine deaminase inhibitors enhance cerebral anoxic hyperemia in the rat. J. Cereb. Blood Flow Metab. 5, 295-299.

Bhaumik, D., Medin, J., Gathy, K. and Coleman, M. S. (1993) Mutational analysis of active site residues of human adenosine deaminase. J. Biol. Chem. 268, 5464-5470.

Blum, U. and Schwedt, G. (1998) Inhibition behavior of acid phosphatase, phosphodiesterase I and adenosine deaminase as tools for trace metal analysis and specification. Anal. Chim. Acta 360, 101-108.

Brady, T. G., OSullivan, W. (1967) A purification of adenosine deaminase from the superficial mucosa of calf intestinal. Biochim. Biophys. Acta 132, 127-137.

Centelles, J. J., Franco, R. and Bozal, J. (1988) Purification and partial characterization of brain adenosine deaminase: inhibition by purine compounds and by drugs. J. Neurosci. Res. 19, 258267.

Chang, Z., Nygaard, P., Chinualt, A. C. and Kellems, R. E. (1991) Deduced amino acid sequence of Escherichia coli adenosine deaminase reveals evolutionarily conserved amino acid residues: implications for catalytic function. Biochemistry 30, 2273-2280.

Cooper, B. F., Sideraki, V., Wilson, D. K., Dominguez, D. Y., Clark, S. W., Quiocho, F. A. and Rudolph, F. B. (1997) The role of divalent cations in structure and function of murine adenosine deaminase. Protein Sci. 6, 1031-1037.

Daddona, P. E., Kelley, W. N. (1978) Human adenosine deaminase binding protein. Assay, purification and properties. J. Biol. Chem. 253, 4617-4623.

Doddona, P. E., Schewach, D. S., Kelly, W. N., Argos, P., Markham, A. F. and Orkin, S. H. (1984) Human adenosine deaminase. cDNA and complete primary amino acid sequence. J. Biol. Chem. 259,12101-12106.

Glazer, R. I. (1980a) Adenosine deaminase inhibitors: their role in chemotherapy and immunosuppersion. Cancer Chemother. Pharmacol. 4, 227-235.

Glazer, R. I. (1980b) 2'-Deoxycoformycin and other adenosine deaminase inhibitors. Rev. Drug Metab. Drug Interact. 3, 105128.

Giblett, E. R., Anderson, J. E., Cohen, F., Pollara, B. and Meuwissen, H. J. (1972) Adenosine deaminase deficiency in two patients with severely impaired cellular immunity. Lancet 2, 1067-1069.

Hirchhorn, R. and Ratech, H. (1980) Isoenzymes of adenosine deaminase; in Isoenzymes: Current Topics in Biological and Medical Research, Rattazi M. C., Scandalia J. G. and Whitt G. S. (eds.), pp. 132-157, Alan R. Liss, New York.

Kaplan, N. O. (1955) Specific adenosine deaminase from intestinal. Methods in Enzymology 2, 473-480, Academic Press, New York

Lee, N., Russel, N. H., Ganeshaguru, K., Jackson, B. F. A., Piga, A., Prentice, H. G., Foa, R. and Hoffbrand, V. (1984) Mechanism of deoxyadenosine toxicity in human lymphoid cells in vitro: relevance to the therapeutic use of inhibitors of adenosine deaminase. Br. J. Haemat. 56, 107-119.

McIlwain, H. (1983) Central nervous system studies on metabolic regulation and function; in Central Nervous System, Genazzari, E. and Herken, H. (eds.), pp. 3-11, Springer-Verlag, New York.

Moosavi-Movahedi, A. A., Rahmani, Y. and Hakimelahi, G. H. (1993) Thermodynamic and kinetic studies of competitive inhibition of adenosine deaminase by using ring opened analogues of adenosine nucleoside. Int. J. Biol. Macromol. 15, 125-129.

Murray, J. L., Loftin K. C., Munn, C. G., Reuben, J. M., Mansell, P. W. A., Hersh, E. M. (1985) Elevated adenosine deaminase and purine nucleoside phosphorilase activity in peripheral blood null lymphocytes from patients with acquired immune deficiency syndrome. Blood 65, 1318-1324.

Stone, T. W. (1989) Purine receptors and their pharmacological roles. Adv. Drug Res. 18, 291-429.

Valentine, W. N., Paglia, D. E., Tartaglia, A. P. and Gilson, F. (1977) Hereditary hemolytic anemia with increased red cell adenosine deaminase (45 to 70 -fold) and decreased adenosine triphosphate. Science 195, 783-786.

Wilson, D, K., Rudolph, F. B., Quiocho, F. A. (1991) Atomic structure of adenosine deaminase with transition-state analogs: understanding catalysis and immunodeficiency mutations. Science 252, 1278-1284. 